\section{Resting Chest Pain, Negative Treadmill Excercise Electrocardiogram, and Reverse Redistribution in Dipyridamole Myocardial Perfusion Scintigraphy Might Be the Features of Coronary Artery Spasm}

\author{
Xiang D-C, Yin J-L, He J-X, Gong Z-H: Clin Cardiol \\ 2007;30:552-526
}

\section{To the Editor:}

I read with interest the article by Xiang et al. from China. ${ }^{1}$ I am extremely pleased to see that Xiang et al. who previously published their work in Chinese in a Chinese journal of nuclear medicine ${ }^{2}$ have now collected a larger series of patients and published their work in your journal. Now this important work can be repeated by other Western investigators in this field.

Coronary artery spasm is an important cause of chest pain in the general population throughout the world. Until now, such a diagnosis could only be made by coronary arteriography, ${ }^{3-5}$ which is invasive. If this noninvasive test could be validated by a larger series of patients, by investigators in other parts of the world, it would be an enormous advance in the diagnosis and treatment of patients with coronary artery disease.

Incidentally, I wish to point out a printing error in the Summary. In the Conclusion, an incorrect abbreviation was used for treadmill exercise echocardiography. Instead of TEEC, which was used throughout the text, it was abbreviated as TEE. The latter usually stands for transesophageal echocardiography.

Tsung O. Cheng, MD George Wasington University, 2150 Pennsylvania Avenue NW, Washington, DC, USA

\section{References}

1. Xiang D -C, Yin J -L, He J -X, Gong Z -H: Resting chest pain, negative treadmill exercise electrocardiogram, and reverse redistribution in dipyridamole myocardial perfusion scintigraphy might be the features of coronary artery spasm. Clin Cardiol 2007;30:522-526

2. Xiang DC, Yin JL, He JX, Teng AP, Gong ZH, et al.: Characteristics of treadmill exercise electrocardiography and dipyridamole ${ }^{201} \mathrm{Tl}$ myocardial perfusion image in patients with coronary artery spasm. Zhonghua Heyixue Zazhi 2005;25:10-13

3. Cheng TO: Ergonovine test for coronary artery spasm. Int J Cardiol 2007;114:249-250

4. Cheng TO, Yasue H: Coronary artery spasm. In: Cheng TO: ed. The International Textbook of Cardiology Oxford/New York: Pergamon Press 1987; 621-637

5. Cheng TO: Coronary artery spasm-1984. Chest $1984 ; 86: 918-926$

CardioWorking.com is the leading cardiology job board
providing free access to the best selection of opportunities
nationwide from both employers and agencies.
The confidential platform provides physicians and specialists
unique tools to gather information about opportunities
while remaining in control of their search and
keeping their information private.
CardioWorking $\boldsymbol{H e l p s}$ You Be in a Position of Choiced
1. Choose from the greatest selection of opportunities.
2. Choose what is known about you.
3. Choose what information you receive about opportunities.
Give the site a test drive and decide today how to
control your search.
(877) 723-7823

\begin{tabular}{|} 
CLASSIFIED ADVERTISING \\
YOUR AD HERE! \\
For more information on placing your classified \\
advertisment in the next available issue, contact: \\
Jennifer Johnson, 781-388-8512 \\
jjohnson@wiley.com
\end{tabular}

\section{INDEX TO ADVERTISERS}

Atacand $170-\mathrm{C} 3, \mathrm{C} 4$

Daiichi Sankyo Eli Lilly

Forest Laboratories. 135,136

Sanofi Aventis A4-A5

Classified Advertising 169

This index is provided as a service. Every effort to achieve accuracy is made. Publisher is not responsible for errors or omissions. 